\title{
Violence toward health workers in Bahrain Defense Force Royal Medical Services' emergency department
}

This article was published in the following Dove Press journal:

Open Access Emergency Medicine

8 November 2017

Number of times this article has been viewed

\author{
Faisal Rafeea' \\ Ahmed Al Ansari ${ }^{2-4}$ \\ Ehab M Abbas' \\ Khalifa Elmusharaf ${ }^{5}$ \\ Mohamed S Abu Zeid' \\ 'Emergency Department, Bahrain \\ Defense Force Hospital, Riffa, Bahrain; \\ ${ }^{2}$ Training and Education Department. \\ Bahrain Defense Force Hospital, \\ Riffa, Bahrain; ${ }^{3}$ Department of \\ General Surgery, College of Medicine \\ and Medical Science, Arabian Gulf \\ University, Manama, Bahrain; ${ }^{4}$ Medical \\ Education Department, Royal College \\ of Surgeons in Ireland - Medical \\ University of Bahrain, Busaiteen, \\ Bahrain; ${ }^{5}$ Graduate Entry Medical \\ School, University of Limerick, Ireland
}

Correspondence: Ahmed Al Ansari Bahrain Defense Force Hospital, Off Waly Alahed Avenue, PO Box 28743,

West Riffa, Bahrain

Tel +973 17766666

Email drahmedalansari@gmail.com
Background: Employees working in emergency departments (EDs) in hospital settings are disproportionately affected by workplace violence as compared to those working in other departments. Such violence results in minor or major injury to these workers. In other cases, it leads to physical disability, reduced job performance, and eventually a nonconducive working environment for these workers.

Materials and methods: A cross-sectional exploratory questionnaire was used to collect data used for the examination of the incidents of violence in the workplace. This study was carried out at the ED of the Bahrain Defense Force (BDF) Hospital. Participants for the study were drawn from nurses, support staff, and emergency physicians. Both male and female workers were surveyed. Results: The study included responses from 100 staff in the ED of the BDF Hospital in Bahrain (doctors, nurses, and support personnel). The most experienced type of violence in the workers in the past 12 months in this study was verbal abuse, which was experienced by $78 \%$ of the participants, which was followed by physical abuse (11\%) and then sexual abuse (3\%). Many cases of violence against ED workers occurred during night shifts (53\%), while physical abuse was reported to occur during all the shifts; $40 \%$ of the staff in the ED of the hospital were not aware of the policies against workplace violence, and $26 \%$ of the staff considered leaving their jobs at the hospital.

Conclusion: This study reported multiple findings on the number of workplace violence incidents, as well as the characteristics and factors associated with violence exposure in ED staff in Bahrain. The results clearly demonstrate the importance of addressing the issue of workplace violence in EDs in Bahrain and can be used to demonstrate the strong need for interventions. Keywords: emergency department, hospital safety, nurses, verbal and physical violence, workplace violence, Bahrain

\section{Introduction}

The potential of workplace violence to negatively affect the performance of an organization makes it a very serious issue that must be studied and addressed from all dimensions and in all sectors. Compared with other sectors, the health care sector seems to be more affected by workplace violence. ${ }^{1}$ In total, $25 \%$ of all cases of workplace violence are reported to occur in health care settings, ${ }^{1}$ and $50 \%$ of individuals working in the health care settings have reported to be affected by one or another form of workplace violence. The highest cases of workplace violence in health care settings are reported to occur in the emergency department (ED). ${ }^{2}$ Many cases of violence in the health care settings go unreported, and thus, the actual rate of the violence cases 
might be higher than the reported figures. ${ }^{3}$ Patients in the ED and their visitors are the main perpetrators of violence toward health care workers. ${ }^{2}$ This is partly due to the stress that results from a loved one who needs emergency care in addition to lack of 24-hour security and stressing working conditions in the ED. ${ }^{2}$

Workplace violence is defined as an act of aggression toward a person during his or her employment, and it can take many forms such as aggression, harassment, bullying, intimidation, or assault. ${ }^{4-6}$ Physical violence may take the form of pushing, scratching, hitting, kicking, pulling, or punching. On the other hand, verbal violence takes the form of calling offensive names, yelling, or verbal threats. ${ }^{7}$ Nurses are at a higher risk in experiencing workplace violence as compared to trainees and nonprovider staff. ${ }^{8}$ Violence perpetrated toward health care workers may result in minor or major physical injury, physical disability, and psychological trauma, and in extreme cases, it may cause death. ${ }^{7}$ In addition, workplace violence is a cause of the low morale among employees, reduced employee productivity and creativity, higher turnover, increased desire to quit jobs, and in other cases the creation of a work environment that is hostile and nonconducive. ${ }^{7}$ It is expected that any form of violence in health care setting will influence the care and treatment of patients. For this reason, addressing incidences of workplace violence is important. ${ }^{9}$ There is evidence of workplace violence toward nurses in psychiatric wards in Bahrain. ${ }^{10}$ However, there are relatively few studies on workplace violence in EDs in general hospitals in Bahrain. In this article, a study of the workplace violence in EDs of hospitals in Bahrain is provided. This study looks at various characteristics of workplace violence including the rate of occurrence, the characteristics of the perpetrator, victims' perceived causes of violent behavior, time period, and effect of such violence on staff working in the ED. Both verbal violence and physical violence are investigated. The context of the study is based on the ED of the Bahrain Defense Force Royal Medical Services.

Bahrain is located in the Arabian Gulf Region. The population in Bahrain is estimated to be 1.33 million, and most of the people are Arab Muslims. ${ }^{11}$ This study provides an examination of workplace violence in the ED of the Bahrain Defense Force (BDF) Hospital. In total, 120 people work in the ED of the BDF Hospital having a bed capacity of 45. In a day, the ED of this hospital admits an average of 12 patients. At the end of this study, the authors will provide recommendations that staff working in the EDs can use to prevent violence against them and minimize cases of violence in the course of their work.

\section{Materials and methods}

The study employed a cross-sectional, exploratory, questionnaire-based methodology to collect data on workplace violence in the ED of the BDF Hospital in Bahrain, which accepts cases from the military population as well as the general population. This study followed a stratified sampling style in which only workers with at least 2 months of experience in the hospital's ED were selected for the study. These included doctors (attending emergency physicians), nurses, and supporting staff such as cashiers, clerks, receptionists, and security personnel. The participants included 100 workers in the ED, and half of them were between the age of 30 and 40 . Of the participants, $66 \%(n=66)$ were female and $34 \%(n=34)$ were male. Participants were recruited by being personally asked by the researchers if they would like to participate in the study. The majority of the participants were nurses $(62 \% ; n=62)$ with a bachelor's degree, followed by physicians $(29 \% ; n=29)$ and then support personnel $(9 \% ; n=9)$. Table 1 includes the full characteristics of the participants.

This study was approved by the Research and Research Ethical Committee of the BDF Hospital. Before participating in the study, the participants were asked to sign a consent form with the assurance from the researchers that their responses will be kept anonymous. The participants were recruited by being personally approached and asked by the researchers if

Table I Participants' characteristics $(n=100)$

\begin{tabular}{lll}
\hline Variable & Classification & Frequency (\%) \\
\hline Gender & Male & $34(34.0)$ \\
Age & Female & $66(66.0)$ \\
& $<30$ years & $23(23.0)$ \\
& $30-40$ years & $54(54.0)$ \\
Marital status & $>40$ years & $23(23.0)$ \\
& Single & $30(30.0)$ \\
& Married & $66(66.0)$ \\
Position in the & Divorced/separated/widowed & $4(4.0)$ \\
ED & Nemergency physicians & $29(29.0)$ \\
& Nurses & $62(62.0)$ \\
Educational & Completed primary or secondary & $9(9.0)$ \\
qualification & schooling & $7(7)$ \\
& Nursing degree & $57(57)$ \\
& University bachelor & $11(11)$ \\
& MSc/PhD & $5(5)$ \\
& Attending emergency physician & $4(4)$ \\
Total years of & House staff & $16(16)$ \\
experience in & $5-10$ & $38(38)$ \\
ED (years) & $>10$ & $42(42)$ \\
\hline Abbering & $20(20)$ \\
\hline
\end{tabular}

Abbreviation: ED, emergency department. 
they would like to participate in the study. If the participants agreed to participate, they were handed out the survey.

This study follows the methodology of a previous study that assessed the characteristics of workplace violence in Lebanon over a period of 12 months. ${ }^{8}$ The survey used in this study collected data on verbal abuse, physical abuse, and sexual abuse directed at staff in the past 12 months in the ED of the BDF Hospital. The survey is composed of three major sections: demographic and professional background (15 questions), exposure to violence (22 questions), and levels of burnout assessed by the Maslach Burnout Inventory (MBI). ${ }^{12}$ Exposure to violence includes responding to several statements about the violence experienced including having the participant choose from six possible causes of violence by_the perpetrator (eg, waiting time and drugs), as well as responding to statements regarding the outcome of violence, awareness of hospital anti-violence policies, and reporting whether they took action or reported their cases. The MBI is a validated tool in assessing burnout that has been used in many countries. ${ }^{12-14}$ It is composed of 22 items divided into three subscales: emotional exhaustion, depersonalization, and professional efficacy. ${ }^{12}$ Responses include rating on a 7-point scale from never (score $=0$ ) to daily (score $=6$ ), that is, how often the participant feels certain experiences. The scores for each of the subscale are added, and the overall score is compared with cutoff points to classify the level of burnout as high, average, or low. ${ }^{12}$

\section{Statistical analysis}

The SPSS Version 19.0 statistical package (IBM Corporation, Armonk, NY, USA) was used for all statistical calculations. Descriptive analyses were performed based on the calculation of frequencies and percentages. In the bivariate analysis, $\chi^{2}$ or Fisher's exact test was used to calculate the association between exposure to each of the physical, verbal, and sexual abuses and the participants' characteristics. Multivariate logistic regression model was used to examine the risk factors associated with exposure to physical and verbal abuse. A significant difference was assumed when $p<0.05$.

\section{Results}

A total of 120 surveys were distributed in this study, and 100 surveys were collected back by the researchers. Those who did not meet the criteria for participation were not allowed to participate in the study. There was a $100 \%$ response rate, no participants were excluded from the study because there were no missing data, and the criteria for participation were clearly explained.

Table 2 shows that verbal abuse was the most common type of violence experienced by the participants $(78 \% ; n=78)$ followed by physical abuse $(11 \% ; n=11)$ and then sexual harassment $(3 \% ; n=3)$. In this study, female employees experienced more verbal abuse $(83 \%$; $n=55)$ than males $(68 \%$; $\mathrm{n}=23 ; \mathrm{OR}=2.391,95 \% \mathrm{CI}=0.6909-6.290, p=0.077)$. In the case of physical violence, both male and female experienced

Table 2 Prevalence of violence among hospital personal

\begin{tabular}{|c|c|c|c|c|c|c|c|c|c|c|}
\hline \multicolumn{2}{|c|}{ Variables } & \multicolumn{3}{|c|}{ Verbally abused } & \multicolumn{3}{|c|}{ Physical abused } & \multicolumn{3}{|c|}{ Sexually abused } \\
\hline & & \multirow{2}{*}{$\frac{\text { Yes }}{\text { n (\%) }}$} & \multirow{2}{*}{$\frac{\text { No }}{\text { n (\%) }}$} & \multirow[t]{2}{*}{ Total } & \multirow{2}{*}{$\frac{\text { Yes }}{n(\%)}$} & \multirow{2}{*}{$\frac{\text { No }}{\text { n (\%) }}$} & \multirow[t]{2}{*}{ Total } & \multirow{2}{*}{$\frac{\text { Yes }}{\text { n (\%) }}$} & \multirow{2}{*}{$\frac{\text { No }}{\text { n (\%) }}$} & \multirow[t]{2}{*}{ Total } \\
\hline & & & & & & & & & & \\
\hline \multicolumn{2}{|c|}{ Prevalence of violence } & $78(78.0)$ & $22(22.0)$ & 100 & II (II.0) & $89(89.0)$ & 100 & $3(3.0)$ & $97(97.0)$ & 100 \\
\hline \multirow[t]{4}{*}{ Age } & $<30$ years & $17(73.90)$ & $6(26.10)$ & 23 & 0 & $23(100)$ & 23 & $\mathrm{I}(4.3)$ & $22(95.7)$ & 23 \\
\hline & $30-40$ years & $42(77.80)$ & $12(22.20)$ & 54 & $7(13.0)$ & $47(87.0)$ & 54 & $2(3.7)$ & $52(96.3)$ & 54 \\
\hline & $>40$ years & $19(82.60)$ & $4(17.40)$ & 23 & $4(17.4)$ & $19(82.6)$ & 23 & 0 & $23(100)$ & 23 \\
\hline & $p$-value ${ }^{a}$ & 0.775 & & & 0.134 & & & 0.623 & & \\
\hline \multirow[t]{3}{*}{ Gender } & Male & $23(67.60)$ & II (32.40) & 34 & $4(I \mid .8)$ & $30(88.2)$ & 34 & 0 & $34(100)$ & 34 \\
\hline & Female & $55(83.30)$ & II (I6.70) & 66 & $7(10.6)$ & $59(89.4)$ & 66 & $3(4.5)$ & $63(95.5)$ & 66 \\
\hline & $p$-value ${ }^{a}$ & 0.073 & & & 0.86 & & & 0.2 & & \\
\hline Marital & Single & $23(76.70)$ & $7(23.30)$ & 30 & $5(16.7)$ & $25(83.3)$ & 30 & $2(6.7)$ & $28(98.3)$ & 30 \\
\hline \multirow[t]{3}{*}{ status } & Married & $51(77.30)$ & $15(22.70)$ & 66 & $6(9.1)$ & $60(90.9)$ & 66 & $\mathrm{I}(1.5)$ & $65(98.5)$ & 66 \\
\hline & $\begin{array}{l}\text { Divorced/separated/ } \\
\text { widowed }\end{array}$ & $4(100.0)$ & 0 & 4 & 0 & $4(100.0)$ & 4 & 0 & $4(100.0)$ & 4 \\
\hline & $p$-value ${ }^{a}$ & 0.55 & & & 0.422 & & & 0.366 & & \\
\hline Position & Emergency physicians & $23(79.30)$ & $6(20.70)$ & 29 & $3(10.3)$ & $26(89.7)$ & 29 & I (3.4) & $28(96.6)$ & 29 \\
\hline \multirow[t]{3}{*}{ in $E D$} & Nurses & $49(79.0)$ & $13(21.0)$ & 62 & $6(9.7)$ & $56(90.3)$ & 62 & $2(3.2)$ & $60(96.8)$ & 62 \\
\hline & Supporting personnel & $6(66.70)$ & $3(33.30)$ & 9 & $2(22.2)$ & 7 (77.8) & 9 & 0 & $9(100)$ & 9 \\
\hline & $p$-value ${ }^{a}$ & 0.69 & & & 0.52 & & & 0.86 & & \\
\hline
\end{tabular}

Note: ${ }^{a} p$-value from $\chi^{2}$ analysis.

Abbreviation: ED, emergency department. 
an equal percentage of violence rate $(12 \%[\mathrm{n}=4]$ vs $11 \%$ $[n=7])$. However, all the cases of sexual violence were experienced by only female participants. The results show that none of the variables were significantly associated with the different forms of violence in ED. Irrespective of the position in ED, majority of the staffs experienced verbal abuse in their service in the ED.

From a total of 78 verbal and 11 physical abuse, some of the participants experienced violence more than others. Some experienced verbal and physical abuse one to three times. In total, $53 \%$ (41 of 78) of verbal abuses occurred during night shifts, while $18 \%$ (2 of 11) of physical violence occurred across all the three shifts; $92 \%$ (72 of 78) of verbal abuse occurred during weekdays, while $100 \%$ (11 of 11 ) of physical violence occurred on weekdays. The majority of all forms of violence in this study occurred either in the examination room or in the area in the ED where the priority of the patient is determined based on the severity of their conditions. ${ }^{15}$

Perpetrators of violence against health workers in this study were found mainly to be patients who demanded special attention and care and thus complained more if they did not receive it and their relatives. In total, $87 \%(n=68)$ of verbal abuse came from demanding patients, while $82 \%(n=9)$ of the physical violence was perpetrated by demanding patients; $49 \%(n=38)$ of the verbal abuse came directly from patients, while $78 \%(n=61)$ of the verbal abuse came from patients' family members or friends. In case of physical violence, patients were directly involved in $46 \%(n=5)$ of the cases, while their relatives and friends were involved in $63 \%(n=7)$ of the violence cases.

Table 3 presents the characteristics of violence. The most common types of verbal abuse toward health care staff were shouting and demands at $81 \%(n=63)$ and $40 \%(n=31)$, respectively. Verbal abuse was also manifested in terms of the threats and outbursts. In regard to physical violence, the perpetrators were described as to making body moves or gestures, which was reported by $55 \%(n=6)$ of the staff. Physical violence in the form of pushing, punching, and grabbing came second with $36 \%(n=4)$, followed by attacks with an object also at $36 \%(n=4)$.

Although many reported cases of physical violence, only one reported such injury. The various forms of violence

Table 3 Characteristics of violence

\begin{tabular}{|c|c|c|c|}
\hline \multirow[t]{2}{*}{ Characteristics of violence } & \multirow[t]{2}{*}{ Classification } & \multirow{2}{*}{$\begin{array}{l}\text { Verbally abused }(n=78) \\
n(\%)\end{array}$} & \multirow{2}{*}{$\begin{array}{l}\text { Physically assaulted }(\mathrm{n}=\mathrm{I} \mathrm{I}) \\
\mathrm{n}(\%)\end{array}$} \\
\hline & & & \\
\hline \multirow[t]{5}{*}{ Frequency } & $\mathrm{I}-3$ times & $24(30.8)$ & $5(45.5)$ \\
\hline & 4-9 times & $10(12.8)$ & 0 \\
\hline & $10-15$ times & $6(7.7)$ & 0 \\
\hline & $>15$ times & $22(28.2)$ & 0 \\
\hline & Cannot remember & $16(20.5)$ & $6(54.5)$ \\
\hline Time of violence during the & Day shift & $2(2.6)$ & $2(18.2)$ \\
\hline \multirow[t]{3}{*}{ day } & Evening shift & $29(37.2)$ & $2(18.2)$ \\
\hline & Night shift & $41(52.6)$ & $2(18.2)$ \\
\hline & Missing & $6(7.7)$ & $5(45.5)$ \\
\hline \multirow[t]{2}{*}{ Day of the week } & Weekend & $6(7.7)$ & 0 \\
\hline & Weekday & $72(92.3)$ & II (100) \\
\hline \multirow[t]{6}{*}{ Place of violence } & Triage area & $37(47.4)$ & $6(54.5)$ \\
\hline & Waiting room & $3(3.8)$ & 0 \\
\hline & Examination room & $28(35.9)$ & $4(36.4)$ \\
\hline & Lobby & $2(2.6)$ & 0 \\
\hline & Hallway & $6(7.7)$ & I (9.1) \\
\hline & Outside the ED & $2(2.6)$ & 0 \\
\hline \multirow[t]{5}{*}{ Classification of perpetrator } & Mental health condition & $2(2.6)$ & I (9.I) \\
\hline & Alcohol abuse & $6(7.7)$ & I (9.I) \\
\hline & Demanding patient & $68(87.2)$ & $9(81.8)$ \\
\hline & Traumatized family member and friends & $19(24.4)$ & 0 \\
\hline & Burnout and exhaustion & $14(17.9)$ & $\mathrm{I}(9.1)$ \\
\hline \multirow[t]{5}{*}{ Type of perpetrator } & Patient & $38(48.7)$ & $5(45.5)$ \\
\hline & Patient's family and/or friends & $61(78.2)$ & $7(63.6)$ \\
\hline & Coworker & $2(2.6)$ & I (9.I) \\
\hline & Supervisor & $4(5.1)$ & 0 \\
\hline & General public & $5(6.4)$ & 0 \\
\hline
\end{tabular}

Abbreviation: ED, emergency department. 
toward health care workers in the ED were then related to the patient's urgency using the Canadian Triage and Acuity Scale. ${ }^{15}$ This index classifies patients into five major categories of urgency of being attended to by putting into consideration both the available resources and patient acuity. The five categories are the following: 1) resuscitation; 2) emergent; 3) urgent; 4) less urgent; and 5) nonurgent. Patients in category 1 have the highest urgency, while patients in category 5 are nonurgent and will not be given priority. Patients in stage III or IV were involved in $27 \%(n=3)$ of the reported cases of physical assault; $3 \%$ of the entire sample reported sexual harassment, while some of them noted that their colleagues had mentioned to them about sexual harassment. In the majority of the sexual harassment cases, men were the perpetrators, while women were victims.

Table 4 provides an explanation of the consequences of violence cases in the ED. Many of the victims of the various forms of violence studied here reported feeling emotionally exhausted. It was found that $26 \%(n=26)$ of the staff had thought of quitting their jobs, while $22 \%(n=22)$ of the staff were considering quitting their jobs in the ED specifically. The various cases of violence made $16 \%(n=16)$ of the staff face difficulty in relating with the family of the patient, while $32 \%(n=32)$ of the staff had requested the police to help them.

To enrich the findings of this study, an item asking the participants to give their opinions on the causes of violence in the ED was included in the study. In total, 92\% $(n=100)$ of the participants noted that the patient waiting time was the major factor that was contributing to the occurrence of

Table 4 Outcome of violence assessment $(n=100)$

\begin{tabular}{ll}
\hline Questions & $\mathbf{n ~ ( \% )}$ \\
\hline Considered leaving your current hospital position & $26(26.0)$ \\
Considered stopping working in the ED & $22(22.0)$ \\
$\begin{array}{l}\text { Sought or obtained legal counseling support } \\
\text { Obtained any form of personal protection }\end{array}$ & $21(21.0)$ \\
$\begin{array}{l}\text { Encountered difficulty in your relationships and with the } \\
\text { family }\end{array}$ & $22(22.0)$ \\
$\begin{array}{l}\text { Encountered difficulty sleeping } \\
\text { Encountered appetite problems }\end{array}$ & $32(32.0)$ \\
$\begin{array}{l}\text { Encountered substance abuse problems, got prescriptions } \\
\text { to take sleeping aids, anxiety pills, and antidepressants }\end{array}$ & $24(24.0)$ \\
$\begin{array}{l}\text { Required medical attention because of a physical or } \\
\text { psychological damage }\end{array}$ & $7(7.0)$ \\
$\begin{array}{l}\text { Sought or obtained psychological counseling } \\
\text { Attended courses/training in handling violent patients/ } \\
\text { family/friends }\end{array}$ & $3(3.0)$ \\
$\begin{array}{l}\text { Requested helps from the police } \\
\text { Sought a personal protection order or assistance in } \\
\text { obtaining one }\end{array}$ & $32(32.0)$ \\
\hline Ab & $12(12.0)$ \\
\hline
\end{tabular}

Abbreviation: ED, emergency department. violent acts. Waiting was followed by patient expectations (69\%; $n=100)$, alcohol $(43 \% ; n=100)$, and the perception of the perpetrator regarding unmet needs $(42 \% ; n=42)$. Table 5 lists the different motivations for violent behaviors as perceived by staff working in the ED.

High levels of burnout were demonstrated by participants and associated with emotional exhaustion and depersonalization, while low levels of burnout are recorded when it comes to personal accomplishments (Table 6). In total, 23\% $(n=23)$ of the staff in the ED reported high levels of burnout due to emotional exhaustion, while another 19\% $(n=19)$ reported higher level of depersonalization while working in the ED; $60 \%(n=60)$ of the ED staff reported low accomplishment in their personal lives. The personal accomplishment levels for nurses and physicians were $58 \%(n=36)$ and $52 \%(n=15)$, respectively. Nonetheless, no significant differences were reported in terms of emotional exhaustion and depersonalization between these groups of workers (Table 6).

In total, $54 \%(n=42)$ of the victims of violence did not report such cases and preferred to keep quiet, but $90 \%(n=10)$ of them took action when they experienced physical forms of violence. Table 7 provides the various responses to cases of violence.

Regarding anti-violence policies, $40 \%(n=40)$ of the staff in the ED were unaware of such policies in the hospital. In addition, $28 \%(n=28)$ of the study participants indicated that security officers positively supported them when they reported such incidences. Table 8 presents the extent to which the staff at the studied hospital are aware and knowledgeable about policies and guidelines on violence in the workplace.

\section{Discussion}

This study explored workplace violence toward emergency staff in the BDF Hospital in Bahrain. The study gathered

Table 5 ED staff opinion, what provokes violence incidents in the ED $(n=100)$

\begin{tabular}{ll}
\hline Items & $\mathbf{n}(\%)$ \\
\hline Alcohol & $43(43)$ \\
Waiting time & $92(92)$ \\
Drugs & $17(17)$ \\
Staff attitude & $37(37)$ \\
Patients expectation (eg, requiring VIP treatment) & $69(69)$ \\
Perpetrators perception that this will get them what they & $42(42)$ \\
want & $31(31)$ \\
Mental state/illness & $28(28)$ \\
Lack of institutional and national zero tolerance to such & \\
behavior & $35(35)$ \\
Inadequacy of resources allocated to match the needs of & \\
the patients and their relatives & \\
\hline
\end{tabular}

Abbreviation: ED, emergency department. 
Table 6 Level of MBI burnout among ED staff

\begin{tabular}{|c|c|c|c|c|c|c|}
\hline \multirow[t]{2}{*}{ MBI subscale } & \multirow[t]{2}{*}{ Level $^{a}$} & \multicolumn{4}{|l|}{ Job } & \multirow[t]{2}{*}{$\chi^{2}(p$-value $)$} \\
\hline & & Physician, n (\%) & Nurse, n (\%) & Supporting staff, n (\%) & Overall n (\%) & \\
\hline \multirow[t]{3}{*}{ Emotional exhaustion } & Low & $10(34.5)$ & $32(5 \mid .6)$ & $3(33.3)$ & $45(45.0)$ & $0.27 \mathrm{I}$ \\
\hline & Moderate & $9(3 \mid .0)$ & $20(32.3)$ & $3(33.3)$ & $32(32.0)$ & \\
\hline & High & $10(34.5)$ & $10(16.1)$ & $3(33.3)$ & $23(23.0)$ & \\
\hline \multirow[t]{3}{*}{ Depersonalization } & Low & $14(48.3)$ & 37 (59.7) & $2(22.2)$ & $53(53.0)$ & 0.205 \\
\hline & Moderate & $9(31.0)$ & $14(22.6)$ & $5(55.6)$ & $28(28.0)$ & \\
\hline & High & $6(20.7)$ & II (I7.7) & $2(22.2)$ & $19(19.0)$ & \\
\hline \multirow[t]{3}{*}{ Personal accomplishment } & Low & $15(51.7)$ & $36(58.1)$ & $9(100.0)$ & $60(60.0)$ & $0.027 * *$ \\
\hline & Moderate & $5(17.2)$ & $18(29.0)$ & 0 & $23(23.0)$ & \\
\hline & High & $9(3 \mid .0)$ & $8(12.9)$ & 0 & 17 (I7.0) & \\
\hline
\end{tabular}

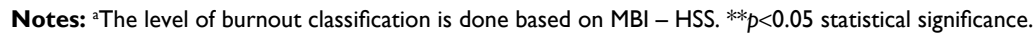

Abbreviations: ED, emergency department; MBI - HSS, Maaslach Burnout Inventory - Human Service Survey.

Table 7 Response to the verbal abuse/physical assault

\begin{tabular}{|c|c|c|c|c|}
\hline \multirow[t]{2}{*}{ Action taken } & \multicolumn{2}{|c|}{ Verbal abuse $(n=78)$} & \multicolumn{2}{|c|}{ Physical assault $(n=I I)$} \\
\hline & Yes & No & Yes & No \\
\hline Took no action & $42(53.8)$ & $36(46.2)$ & $I(9.1)$ & $10(90.9)$ \\
\hline Told the person to stop & $46(59.0)$ & $32(41.0)$ & $4(36.4)$ & $7(63.6)$ \\
\hline Tried to defend yourself & $39(50.0)$ & $39(50.0)$ & $3(27.3)$ & $8(72.7)$ \\
\hline Shouted back at the patient & $12(15.4)$ & $66(84.6)$ & $3(27.3)$ & $8(72.7)$ \\
\hline Became mean or sarcastic in your response & $8(10.3)$ & $70(89.7)$ & $3(27.3)$ & $8(72.7)$ \\
\hline Walked away from the scene and avoided the patient from that point on & $29(37.2)$ & $49(62.8)$ & $5(45.5)$ & $6(54.5)$ \\
\hline Reported to family/friends/colleagues & $28(35.9)$ & $50(64.1)$ & $4(36.4)$ & $7(63.6)$ \\
\hline Reported to ED/hospital superior/supervisor & $43(55.1)$ & $35(44.9)$ & $4(36.4)$ & $7(63.6)$ \\
\hline Completed incident report & $24(30.8)$ & $54(69.2)$ & $3(27.3)$ & $8(72.7)$ \\
\hline Ask for transfer to another department & $6(7.7)$ & $72(92.3)$ & $4(36.4)$ & $7(63.6)$ \\
\hline Asked to leave current position at this hospital & $6(7.7)$ & $72(92.3)$ & $3(27.3)$ & $8(72.7)$ \\
\hline Reported to police & $17(21.8)$ & $61(78.2)$ & $3(27.3)$ & $8(72.7)$ \\
\hline Took legal action against perpetrator & $10(12.8)$ & $68(87.2)$ & $4(36.4)$ & $7(63.6)$ \\
\hline
\end{tabular}

Abbreviation: ED, emergency department.

Table 8 Staff knowledge about hospital/ED anti-violence policies and regulation

\begin{tabular}{|c|c|c|c|c|c|c|}
\hline Questions & Yes & $\begin{array}{l}\text { Yes }- \text { Not } \\
\text { always, but } \\
\text { adequately } \\
\text { enough }\end{array}$ & No & Sometimes & Inadequately & $\begin{array}{l}\text { Do not } \\
\text { know }\end{array}$ \\
\hline $\begin{array}{l}\text { Do the hospital/ED has specific anti-violence policies and } \\
\text { regulations? }\end{array}$ & $36(36)$ & & $24(24)$ & & & $40(40)$ \\
\hline Are the ED staff aware of these policies and regulations? & $30(30)$ & & $27(27)$ & & & $43(43)$ \\
\hline Are these policies and regulations being implemented? & $15(15)$ & & $35(35)$ & & & $50(50)$ \\
\hline $\begin{array}{l}\text { Are your protection or security officers actively supporting you } \\
\text { and protecting you from violence? }\end{array}$ & $28(28)$ & & $49(49)$ & & & $23(23)$ \\
\hline $\begin{array}{l}\text { Are your protection or security officers adequately supporting } \\
\text { you and protecting you from violence? }\end{array}$ & $9(9)$ & $22(22)$ & $25(25)$ & $32(32)$ & $\mathrm{II}(\mathrm{II})$ & $I(I)$ \\
\hline
\end{tabular}

Abbreviation: ED, emergency department.

data on the prevalence, characteristics, and factors related to workplace violence over the past 12 months. An example of such characteristics includes data on the number of occurrences for different types of violence, gender differences, and differences in health care workers' occupations. In addition, in order to provide direction for interventions on reducing workplace violence in this context, this study provided data on the different times and contexts in which workplace violence 
took place most. This study also looked at the perceived cause of violence by the workers to provide further direction for research on the prevention of workplace violence.

The finding in this study demonstrates high cases of violence (92 cases in 100 participants) experienced in the ED of the BDF Hospital in Bahrain. Violence affected all types of staff in the ED including doctors, nurses, and supporting staff such as clerks and security personnel. This suggests that workplace violence is a major issue that affects and needs to be addressed in Bahrain. The finding of high workplace violence in health care settings in this study is consistent with past findings and suggests that workplace violence is a major issue in EDs and hospital settings that is evident across different countries. ${ }^{16-19}$ Most of these studies, however, only looked at physical violence. ${ }^{17-19}$ Some studies have found that verbal abuse is highly prevalent toward workers in the workplace, ${ }^{20-22}$ which is supported by the present study by demonstrating that there were many cases of verbal abuse toward workers in the ED. Similar to a past report, there were much higher cases of verbal abuse than physical abuse, supporting the suggestion that verbal abuse is more common than physical abuse in the workplace. ${ }^{20}$

Regarding the characteristics of the victims, there was no significant difference between the number of violent cases in male and female victims in this study $(p=0.077)$. Interestingly, despite literature showing the higher risk of nurses to experience violence, ${ }^{23,24}$ this study found that both doctors and nurses experienced almost the same amount of verbal abuse, physical abuse, and sexual abuse. The supporting staff experienced the least incidents of violence. However, there were very few supporting staff in this study, and therefore, the results should be viewed with caution. This is possibly due to the fact that doctors and nurses have more contact with patients. Moreover, this study also investigated the times and settings in which most violence occurred.

This study also looked at workers' perceived causes of violence to provide directions for studies looking at factors most likely to influence violence in this setting, which could then aid in determining the cause of violence and the development of intervention techniques. Waiting time and patient expectations were the highest causes of violence perceived by the workers found in this study. Past literature found that these factors do in fact influence violence in health care settings. ${ }^{25}$ This study supports the suggestion made by Kwok et al that workplace violence is a reflection of larger organizational and structural problems and suggests that improvements made to organizational structures could prove to be beneficial (which could enhance waiting times). ${ }^{9}$
This study also examined the possible negative effect violence could have on the victim's job and well-being. It was found that $26 \%$ of the staff thought of quitting their job as a result of their experienced violence. This is supported by studies that found high turnover rates and resignation due to workplace violence and suggests the possibility that workplace violence experienced in the ED could lead to negative outcomes such as the desire to quit. ${ }^{26}$ However, although the findings make it likely to suggest the possibility of violence increasing health care staff's likelihood of wanting to quit in the ED in Bahrain, further studies are required to identify whether violence had an influence on increasing staff intention to quit.

Furthermore, this study also obtained measures of burnout. These could possibly be influenced by experience to workplace violence. In this study, $23 \%$ of the staff reported high levels of burnout, and most of the staff reported the feeling of low accomplishment. Thus, these findings provide directions for person-related factors that may be affected by workplace violence and demonstrate the importance of reducing workplace violence.

Moving on, past findings have suggested that most cases of workplace violence go unreported; ${ }^{5,27}$ this is consistent with the findings in this study. However, an interesting distinction was found in whether the victims took some form of action after being abused. More than half of the participants who experienced verbal abuse did not take action, whereas most victims took action if the type of violence experienced was physical.

A possible reason for unreported violence is unawareness of the hospital's anti-violence policies. According to past studies, most of the workplace violence goes unreported. ${ }^{27}$ This study demonstrated that many of the staff (40\%) were unaware of the hospital's anti-violence policies. Thus, it provides a clear approach for interventions to reduce the risk of violence in the ED by providing more awareness on the hospital's anti-violence policies to all the staff.

In addition, another possible reason for unreported violence is the staff's perception of it being a "part of their job" and because it is inconvenient. ${ }^{28}$ Another study suggested that reporting cases of violence consumes time, is not supported by the management, and does not have major effects. ${ }^{29}$ This suggests that the hospital should also provide a more convenient reporting system and remind the staff of their rights. Violence prevention programs and leadership support programs could also be used to achieve a safe environment for the patients and staff. ${ }^{23,30}$ Administrative support could also be beneficial in ensuring that the victims are not afraid of reporting violence due to retribution fears. ${ }^{31}$ 


\section{Conclusion}

Providing information on workplace violence in EDs is crucial for demonstrating the importance of this topic and to push for changes that could protect health care staff. Research in this area is lacking in Bahrain. This study demonstrated the need for interventions to reduce workplace violence in Bahrain by providing data that demonstrated the high frequency of its occurrence. Violence rates and characteristics of the perpetrator, victims, settings, and possible consequences of violence in this study could provide a clear guidance for interventions aimed at reducing violence in Bahrain. In conclusion, this study demonstrates that despite the minimal literature on workplace violence in EDs in Bahrain, this problem is highly important in this region, and changes are required in EDs in Bahrain.

\section{Limitations}

This study has some limitations. First, it relies on self-reported data. There is also the potential of recall bias in that workplace violence may have been underreported or overreported. There is also the case of nonresponse bias in that those who did not respond to survey questions may have experienced one form of workplace violence or another. Another major limitation of this study is that the assessment of working conditions of the staff in the ED was not done. Any future studies on workplace violence in the ED should consider working conditions and correlate it to violence in the ED. This study is also limited in that it used only one method for measuring incidences of workplace violence. In the future, authors should consider the use of multiple methods to gather data so as to obtain solid findings and to overcome the biases of using a single method. The use of convenience sampling is also a limitation in that the results may have low validity and thus not be representative of all workers in the EDs in hospitals in the world. Despite these limitations, the findings obtained in this study are similar to studies conducted previously on workplace violence in the ED.

\section{Author contributions}

FR, AA, EMA, and MSA contributed to the conception and design of the study. FR, EMA, and MSA worked on the data collection. KE and AA contributed to the data analysis and interpretation of the data. AA, KE, and MSA contributed to the drafting of the manuscript. All authors contributed toward data analysis, drafting and revising the paper and agree to be accountable for all aspects of the work.

\section{Disclosure}

The authors report no conflicts of interest in this work.

\section{References}

1. WHO. Workplace violence. World Health Organization. Available from: http://www.who.int/violence_injury_prevention/injury/work9/en/print. html.

2. Gacki-Smith J, Juarez AM, Boyett L, Homeyer C, Robinson L, MacLean SL. Violence against nurses working in US emergency departments. $J$ Healthc Prot Manage. 2010;26:81-99.

3. Rose M. A survey of violence toward nursing staff in one large Irish accident and emergency. J Emerg Nurs. 1997;23:214-219.

4. McPhaul KM, Lipscomb JA. Workplace violence in health care: recognized but not regulated. Online J Issues Nurs. 2004;9:7.

5. Neuman JH, Baron RA. Workplace violence and workplace aggression: evidence concerning specific forms, potential causes, and preferred targets. Journal Manag. 1998;24(3):391-419.

6. Jackson D, Clare J, Mannix J. Who would want to be a nurse? Violence in the workplace - a factor in recruitment and retention. J Nurs Manag. 2002;10(1):13-20.

7. Belayachi J, Berrechid K, Amlaiky F, Zekraoui A, Abouqal R. Violence toward physicians in emergency departments of Morocco: prevalence, predictive factors, and psychological impact. J Occup Med Toxicol. 2010;5:27.

8. Alameddine M, Kazzi A, El-Jardali F, Dimassi H, Maalouf S. Occupational violence in Lebanese emergency departments: prevalence, characteristics and associated factors. J Occup Health. 2011;53: 455-464.

9. Kwok RP, Law YK, Li KE, et al. Prevalence of workplace violence against nurses in Hong Kong. Hong Kong Med J. 2006;12:6-9.

10. Hamadeh RR, Al Alaiwat B, Al Ansari A. Assaults and nonpatientinduced injuries among psychiatric nursing staff in Bahrain. Issues Ment Health Nurs. 2003;24(4):409-417.

11. Census2010.gov.bh [homepage on the Internet]. Bahraini Census 2010; 2017. Available from: http://www.census2010.gov.bh/results_en.php. Available from September 13, 2017.

12. Maslach C, Jackson SE. Maslach Burnout Inventory (2nd edition). Palo Alto, CA: Consulting Psychologists Press; 1986.

13. Ilhan MN, Durukan E, Taner E, Maral I, Bumin MA. Burnout and its correlates among nursing staff: questionnaire survey. $J A d v$ Nurs. 2008;61:100-106.

14. Poghosyan L, Aiken LH, Sloane DM. Factor structure of the Maslach burnout inventory: an analysis of data from large scale cross-sectional surveys of nurses from eight countries. Int J Nurs Stud. 2009;46:894-902.

15. Sands N. An ABC approach to assessing the risk of violence at triage. Australas Emerg Nurs J. 2007;10:107-109.

16. WHO. New Research shows workplace violence threatens health services. Available from: http://www.who.int/mediacentre/news/releases/ release37/en/. Accessed September 12, 2017.

17. Fallahi-Khoshknab M, Oskouie F, Najafi F, Ghazanfari N, Tamizi Z, Afshani S. Physical violence against health care workers: a nationwide study from Iran. Iran J Nurs Midwifery Res. 2016;21:232-238.

18. Abualrub RF, Al-Asmar AH. Physical violence in the workplace among Jordanian hospital nurses. J Transcult Nurs. 2011;22:157-165.

19. Hasani A, Zaheri MM, Abbasi M, Saeedi H, Hosseini M, Fathi M. The incidence rate of physical and verbal violence inflicted by patients and their companions on the Emergency Department Staff of Hazratee-Rasoul Hospital in the fourth trimester of the year 1385. RJMS. 2010;16:46-51.

20. Emergency Nurses Association (ENA). A workplace violence toolkit. Available from: http://www.ena.org/IENR/ViolenceToolKit/Documents/ toolkitpg1.htm. Accessed September 12, 2017.

21. Boyle M, Koritsas S, Coles J, Stanley J. A pilot study of workplace violence towards paramedics. Emerg Med J. 2007;24:760-763.

22. Pozzi C. Exposure of prehospital providers to violence and abuse. J Emerg Nurs. 1998;24:320-323.

23. US Department of Labor, Bureau of Labor Statistics. National Census Of Fatal Occupational Injuries in 2001. USDL 02-541. Washington, DC: US Department of Labor; 2002. 
24. Warchol G. National Crime Victimization Survey: Workplace Violence, 1992-1996. Bureau of Justice Statistics Special Report. Washington, DC: Bureau of Justice; 1998.

25. Crilly J, Chaboyer W, Creedy D. Violence towards emergency department nurses by patients. Accid Emerg Nurs. 2004;12:67-73.

26. Pich J, Hazelton M, Sundin D, Kable A. Patient-related violence against emergency department nurses. Nurs Health Sci. 2010;12:268-274.

27. Kvas A, Seljak J. Unreported workplace violence in nursing. Int Nurs Rev. 2014;61(3):344-351.

28. Bird J. Nurses under-report violence, saying it's a "waste of time". FierceHealthcare. Available from: http://www.fiercehealthcare.com/ healthcare/nurses-under-report-violence-saying-it-s-a-waste-time. Accessed October 17, 2017.
29. Gerberich SG, Church TR, McGovern PM, et al. An epidemiological study of the magnitude and consequences of work related violence: the Minnesota nurses' study. 2004;61:495-503.

30. Ramacciati N, Ceccagnoli A, Addey B, Lumini E, Rasero L. Interventions to reduce the risk of violence toward emergency department staff: current approaches. Open Access Emerg Med. 2016;8:17-27.

31. Stene J, Larson E, Levy M, Dohlman M. Workplace violence in the emergency department: giving staff the tools and support to report. Perm J. 2015;19(2):e113-e117.

\section{Publish your work in this journal}

The Open Access Emergency Medicine is an international, peerreviewed, open access journal publishing original research, reports, editorials, reviews and commentaries on all aspects of emergency medicine. The manuscript management system is completely online and includes a very quick and fair peer-review system, which is all

\section{Dovepress}

easy to use. Visit http://www.dovepress.com/testimonials.php to read real quotes from published authors. 